\title{
Incidencia y severidad de enfermedades asociadas al cultivo de plátano (Musa paradisiaca L.) en Rivas, Nicaragua
}

\section{Incidence and severity of diseases associated to cultivation of bananas (Musa paradisiaca L.) in Rivas, Nicaragua}

\begin{abstract}
Trinidad Castillo-Arévalo ${ }^{1}$, Edgardo Jiménez-Martínez ${ }^{2}$
${ }^{1}$ MSc. en Sanidad Vegetal / ORCID: https://orcid.org/0000-0001-6401-0142 / trinidad.castillo@ci.una.edu.ni

${ }^{2} \mathrm{PhD}$. en Entomología / ORCID: https://orcid.org/0000-0003-1086-7380 / edgardo.jimenez@ci.una.edu.ni Universidad Nacional Agraria
\end{abstract}

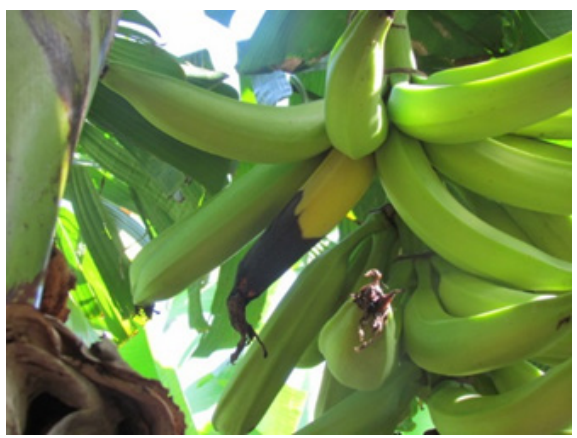

\section{RESUMEN}

En Nicaragua severidad de patógenos que cusan enfermedades en plátano (Musa paradisiaca L.) ha afectado los rendimientos e ingreso que este cultivo proporciona a los pequeños, medianos y grandes productores del país. La seguridad alimentaria que el cultivo proporciona a los productores se ha visto amenazada por enfermedades que afectan a la planta y sus frutos. Con el objetivo de determinar la incidencia y severidad de enfermedades en plátano, se realizó este estudio entre enero a septiembre del 2014 en Rivas. Se hicieron colectas de material enfermo en seis fincas plataneras de Rivas. Los patógenos fueron identificados en los laboratorios del Instituto de Protección y Sanidad Agropecuaria en Rivas y confirmados en laboratorios de la Universidad Nacional Agraria. Las variables evaluadas en este estudio fueron, porcentaje de incidencia y severidad de daño de Sigatoka negra por planta, área bajo la curva de progreso de la enfermedad de Sigatoka negra, porcentaje de incidencia de daño de las enfermedades pudrición acuosa de las musáceas y de punta de cigarro. Como resultados del estudio se identificaron los siguientes patógenos en plátano: Micosphaerella fijiensis, Erwinia sp y Verticillium sp., de manera general se observó que la incidencia y severidad de todos los agentes causales de enfermedades reflejaron un comportamiento similar en las seis fincas, estos agentes se presentaron en todos los meses de muestreo, sin embargo, los mayores porcentajes de severidad se manifestaron en los meses de agosto y septiembre del 2014 con porcentajes que oscilaron entre el $60 \%$ y $67 \%$, la mayor área bajo la curva de progreso de la enfermedad se presentó en la finca La Zopilota, seguido de San Alberto y La Granja, la menor área bajo la curva de progreso de la enfermedad se presentó en la finca El Espíritu, El Trapiche y Valentina.

Palabras clave: musáceas, Micosphaerella fijiensis, Erwinia sp, Verticillium sp.

\section{ABSTRACT}

In Nicaragua, the severity of pathogens that causes diseases on plantain (Musa paradisiaca L.) has affected by reducing the production and income that this crop provides to small, medium and large producers. The food security that the crop provides to the producers has been threatened by diseases that affect the plant and its fruits. In order to determine the incidence and severity of diseases in plantain, this study was carried out between January and September 2014 in Rivas. Collections of diseased material were made in six banana farms in Rivas. The pathogens were identified in the laboratories of the Instituto de Protección y Sanidad Agropecuaria in Rivas and confirmed in laboratories of the Universidad Nacional Agraria. The variables evaluated in this study were, percentage of incidence and severity of black leaf streak disease per plant, area under the progress curve of black leaf streak disease, percentage of damage incidence of watery rot diseases of musaceae and tip. of cigar. As results of the study, the following pathogens in banana were identified: Micosphaerella fijiensis, Erwinia sp and Verticillium $s p$., In general it was observed that the incidence and severity of all disease-causing agents reflected a similar behavior in the six farms, these agents occurred in all sampling months, however, the highest severity percentages were manifested in the months of August and September 2014 with percentages that ranged between $60 \%$ and $67 \%$, the largest area under the progress curve of the The disease occurred at the La Zopilota farm, followed by San Alberto and La Granja, the smallest area under the disease progression curve occurred at the El Espíritu, El Trapiche and Valentina.

Key words: musaceae, Micosphaerella fijiensis, Erwinia sp, Verticillium sp.
Recibido: 23 de octubre del 2019

Aceptado: 10 de marzo del 2020

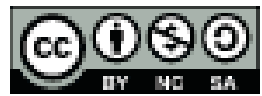

Los artículos de la revista La Calera de la Universidad Nacional Agraria, Nicaragua, se comparten bajo términos de la licencia Creative Commons: Reconocimiento, No Comercial, Compartir Igual. Las autorizaciones adicionales a las aquí delimitadas se pueden obtener en el correo edgardo.jimenez@ci.una.edu.ni 


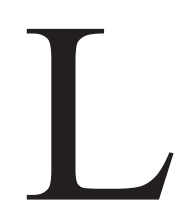

os plátanos pertenecen al género Musa y representan al cuarto cultivo más importante en el mundo, ya que sólo lo superan el arroz, trigo y maíz (Jones, 2000) y es el frutal tropical más importante por su consumo internacional. Estas especies se cultivan en más de 120 países, las cuales producen cerca de 100 millones de toneladas anualmente (HeslopHarrison y Schwarzacher, 2007), los cuales constituyen el principal alimento de al menos 400 millones de personas ya que cuenta con un gran contenido de carbohidratos, vitaminas y minerales. Los países de América Latina son los principales exportadores de fruta fresca hacia los Estados Unidos y Europa.

Según Martínez (2018), el departamento de Rivas posee las mejores condiciones agroclimáticas para la siembra y el establecimiento de explotaciones plataneras bajo riego gracias a las características edáficas y la abundancia del recurso agua subterránea. Rivas tiene la mayor cantidad de áreas sembradas de musáceas del país y en la zona el plátano es un rubro de alta relevancia agrícola, especialmente en la zona de Ometepe, Belén, Potosí, San Jorge, Buenos Aires y Tola donde existen más de 10000 manzanas en producción.

Estudios realizados por (MIFIC, 2009) asegura que el plátano es un cultivo potencialmente de alta rentabilidad, con aceptables índices de producción y calidad, representa un rubro alternativo de exportación en la región, principalmente para el mercado Centroamericano como El Salvador y Honduras donde es utilizado como materia prima y fruta fresca, con precios atractivos el cual lo ubica como un cultivo de alta estabilidad mercantil. Sin embargo, desde algún tiempo atrás, la seguridad que el cultivo proporciona a los pequeños, medianos y grandes productores, se ha visto amenazada por un conjunto de plagas que afectan a la planta y sus frutos (Jiménez-Martínez y Rodríguez, 2014). Las enfermedades foliares, tallo y fruto (Mycosphaerella fijiensis, Erwinia sp y Verticillium $\mathrm{sp}$ ), son el principal problema fitopatológico del cultivo del banano y el plátano en América, Asia y África (Carlier et al. 2000). El objetivo de esta investigación es determinar la incidencia y severidad de enfermedades en plátano, que ayuden en la toma de decisiones y el manejo del cultivo. Esta investigación sirve como base para fortalecer conocimientos científicos y brinda información que puede ser considerada para el diseño de estrategias de manejo integrado de cultivo que sean eficientes y sostenibles.

\section{MATERIALES Y MÉTODOS}

Ubicación de las parcelas experimentales. El estudio se llevó a cabo entre enero a septiembre del 2014, en seis fincas plataneras del departamento de Rivas, estas fincas son propiedades de los productores Familia Pérez dueños de las fincas El espíritu, La Granja, y El Trapiche, el productor Nackxil Zúñiga es el dueño de la finca Valentina), el productor Marlon Aguilar posee la finca San Alberto y el señor Rony Alvarado dueño de la finca La Zopilota.

Descripción y ubicación. En todas las fincas utilizadas en este estudio producen la variedad cuerno enano con sistema de riego y aplicaciones sistemáticas de insumos, este sistema de siembra es utilizado por los pequeños productores de plátano de la zona. Los meses de siembra se extienden de abril a junio, pero con más frecuencia es el mes de agosto por efectos de lluvia y el periodo de corte se realiza todo el año debido a que la siembra se realiza con selección de semillas por bloques, la cosecha generalmente se da a los nueve meses. El grado de maduración de los frutos es bastante visual, se considera cosechar cuando se tiene el $75 \%$ de llenado de racimos con más de 30 dedos. La maduración del fruto hasta la cosecha está determinada por las exigencias del mercado.

Fincas de la Familia Pérez Ubicadas, dos en el Municipio de Potosí y una en Belén, con poblaciones que oscilan entre 1800 y 2000 plantas por manzanas, obteniéndose rendimientos entre las 50000 y 60000 unidades por manzanas.

Finca Valentina. Ubicada en el Municipio de Potosí, con poblaciones que oscilan entre 1600 y 1800 plantas por manzanas, obteniéndose rendimientos entre las 48000 y 54 000 unidades por manzanas. Se considera cosechar cuando tienen un tamaño de fruto de 8 a 9 pulgadas de calibre.

Finca San Alberto. Ubicada en el Municipio de Buenos Aires, con poblaciones que oscilan entre 1600 y 1800 plantas por manzanas, obteniéndose rendimientos entre las $48000 \mathrm{y}$ 54000 unidades por manzanas. Se considera cosechar cuando tienen un tamaño de fruto de 7.5 a 10 pulgadas de calibre.

Finca La Zopilota. Ubicada en el Municipio de Buenos Aires, con poblaciones que oscilan entre 1600 y 1800 plantas por manzanas, obteniéndose rendimientos entre las $48000 \mathrm{y}$ 54000 unidades por manzanas. Se considera cosechar cuando tienen un tamaño de fruto de 7.5 a 9 pulgadas de calibre.

Metodología para el registro de Sigatoka y colecta de muestras. El monitoreo de sigatoka, se realizó quincenalmente, este se hizo colectando partes de la planta (hojas) con signos y síntomas de enfermedades, se utilizó un formato de registro de la cantidad de hojas dañadas encontradas en cada sitio de muestro/día/parcela, luego depositadas dentro de un termo con hielo para el transporte del campo a los laboratorios de fitopatología del IPSA en Rivas y de la UNA en Managua.

\section{Evaluación de sigatoka}

Incidencia. Para determinar el porcentaje de incidencia de enfermedades se utilizó la siguiente fórmula: 


$$
\text { Incidencia }(\%)=\frac{\text { numero de hojas muestreadas con sintomas }}{\text { Total de hojas muestreados }} \times 100
$$

Severidad. Con el fin de facilitar la realización de este estudio, se utilizó una escala para medir el nivel de daño foliar en plátano. Esta escala consistió en la estimación visual del porcentaje afectado de hojas para obtener el grado porcentual de severidad se utilizó la fórmula general planteada por Vanderplank (1968).

$$
S(\%)=\frac{\sum i}{N(\operatorname{Vmax})} \times 100
$$

Donde:

$\mathrm{S}=$ Porcentaje de severidad

$\sum \mathrm{i}=$ Sumatoria de valores observados

$\mathrm{N}$ = Número de plantas muestreadas

Vmax $=$ Valor máximo de la escala

Cuadro 1. Escala de severidad de Micosphaerella fijiensis (sigatoka)

Descripción de sintomas
$\begin{aligned} & \text { Aparecen pequeñas manchas blanquecinas o amarillentas de } \\ & 1 \text { mm de diámetro similar a Sigatoka amarilla, esta mancha } \\ & \text { no es visible tras luz y únicamente se observa en el envés de } \\ & \text { las hojas infectadas. } \\ & \text { Aparece una estría generalmente de color café en el envés } \\ & \text { de las hojas infectadas que más tarde se pueden apreciar } \\ & \text { también en la parte superior del limbo de las hojas como una } \\ & \text { estría de color amarillento que lentamente se torna café a } \\ & \text { negro sobre el haz de las hojas, manteniéndose el color café } \\ & \text { en las estrías en el envés de las hojas. }\end{aligned}$
$\begin{aligned} & \text { Se diferencia del anterior por las dimensiones de las estrias, } \\ & \text { pues estas inician a alongarse, alcanzando bajo óptimas } \\ & \text { condiciones hasta } 2 \text { o } 3 \text { cm de largo. Aqui se inicia la } \\ & \text { formación de conidioforos y producción de conidias. }\end{aligned}$
$\begin{aligned} & \text { Las manchas formadas se observan de color negro en el haz } \\ & \text { de las hojas y café en el envés }\end{aligned}$
Las manchas negras se presentan elipsoides por un halo
amarillo

Fuente: Fouré (1982)
Cálculo del área bajo la curva de progreso de la enfermedad (ABCPE) para sigatoka. Con los registros de severidad por finca se calculó el área bajo la curva de progreso de la enfermedad (ABCPE) para Sigatoka negra. La fórmula utilizada fue la propuesta por (Shaner y Finney, 1977).

$$
A B C P E=\sum_{i=1}^{n-1}\left[\frac{X_{i+1}+X_{i}}{2}\right]\left(t_{i+1}-t_{i}\right)
$$

Donde:

$\mathrm{xi}=$ Porcentaje de tejido afectado

$\mathrm{t}=$ Tiempo (días)

$\mathrm{n}=$ número de evaluaciones

\section{Identificación y descripción de Micosphaerella fijiensis} (Sigatoka negra) en laboratorio

Análisis patológico de material vegetativo. Previo a la identificación y descripción se realizó el análisis patológico del material vegetativo, se utilizaron técnicas de inducción de crecimiento de hongos, a partir de tejido vegetal enfermo posteriormente se sembró en medios de cultivos como: Agar-Agua (AA) y Papa Dextrosa Agar (PDA para inducir la esporulación de estructuras reproductivas del patógeno.

Cámara húmeda. Las muestras de tejido vegetal enfermo (hojas) se colocaron en platos petri o cajas plásticas con papel filtro, humedecido con agua destilada estéril para inducir a la esporulación de estructuras fructíferas de los hongos y su posterior identificación mediante el uso de microscopio.

\section{Siembra de trozos de hojas con estructuras fructíferas} y tejido infectado en AA y PDA. Se tomaron hojas con síntomas, posteriormente se realizaron pequeños cortes en la hoja de manera que solo quedara en la lesión la estructura, luego se dejó reposar en agua destilada estéril por un minuto, se secó con papel filtro y se dejó reposar por 30 segundos, finalmente se sembró en platos petri con Agar-Agua (AA). El fin es el de inducir el desarrollo y crecimiento de estructuras de reproducción, tanto de fase sexual como asexual. Para la siembra de trozos de hojas con tejido infectado en medio de cultivo papa dextrosa agar (PDA), las muestras fueron primeramente desinfectadas en alcohol al $95 \%$ por 1 minuto, luego se sembraron en platos Petri con PDA; estos platos petri se rotularon de la siguiente manera: nombre del cultivo, fecha de muestreo y nombre de la parcela, los platos se preservaron a temperaturas de 25-30 grados centígrados. Se revisaban diariamente con el propósito de observar estructuras reproductivas. 
Identificación de Micosphaerella fijiensis. El género de hongo encontrado fue identificado utilizando claves taxonómicas. Las características morfológicas o de crecimiento se observaron en microscopio (Monterrosa, 1996).

Metodología para el registro de Erwinia sp. El muestreo de Erwinia, se realizó quincenalmente, colectando partes de la planta (pseudotallo) con signos y síntomas de enfermedades, se utilizó un formato de registro de la cantidad de hojas dañadas encontradas en cada sitio de muestro/día/parcela, luego depositadas dentro de un termo con hielo para el transporte del campo a los laboratorios de fitopatología del IPSA en Rivas y de la UNA en Managua.

\section{Evaluación de Erwinia sp.}

Incidencia. Para determinar el porcentaje de incidencia de enfermedades se utilizó la siguiente fórmula:

$$
\text { Incidencia }(\%)=\frac{\text { numero de hojas muestreadas con sintomas }}{\text { Total de hojas muestreados }} \times 100
$$

Identificación y descripción de Erwinia sp. En laboratorio. Para el procesamiento de las muestras en el laboratorio de bacteriología se realizó de la siguiente manera según Fernández, García y Valdezate (2010).

Lavado con agua de grifo introduciendo el material en una bolsa plástica, agitándose suavemente y realizando varios lavados en forma de enjuague hasta que la muestra se observó completamente limpia.

Se seleccionaron áreas de tejido enfermo y se seccionaron con bisturí, cuando se obtuvieron los trozos convenientes para el montaje de las muestras se procedió a desinfectar el material seccionado utilizando hipoclorito de sodio $(\mathrm{NaClo})$ al $5 \%$, con tiempos que van de uno a tres minutos, una vez desinfectada la muestra y previo a la siembra se colocó papel filtro estéril para secar el agua.

La siembra de las muestras se efectuó de la siguiente manera:

Se colocaron los trozos desinfectados (aproximadamente 5 trozos de $2 \mathrm{~cm}$ de largo por plato petri) en el medio de cultivo, se maceró la muestra y se rayó en medio de cultivo.

\section{Medio de cultivo}

Parte I. $\mathrm{K}_{2} \mathrm{PO}_{4}$ (1gm), Peptona de caseína ( $\left.8 \mathrm{gm}\right)$, extracto de levadura (3gm), $\mathrm{NaCl}$ (4gm), agua destilada (900 ml), $\mathrm{pH}=7.0$

Parte II. Agua destilada (100 ml), Glucosa (3 gm).

Preparación. Se homogenizan los ingredientes de la parte Iy se le toma el $\mathrm{pH}$, una vez que el $\mathrm{pH}$ está en el valor requerido (7.0), se procede a licuar el agar incorporado en la parte I del medio; en un baño maría a una temperatura aproximada a $121{ }^{\circ} \mathrm{C}$ por 15 minutos en autoclave. Las dos partes se mezclan cuando el medio tiene una temperatura aproximada $600 \mathrm{C}$. Luego se vierte en platos petri estériles, estos sustratos se realizaron de acuerdo a (Mairena, 2003).

Test de flujo. Se utilizó como prueba rápida, en el caso de bacterias vasculares (pseudotallo). Un trozo del tallo atacado por la bacteria vascular es cortado y se colocó suspendido en un vaso de agua. En este caso Erwinia fluye (se descarga) hacia al agua. Se observa a simple vista.

Identificación de Erwinia sp. Se valoraron parámetros: Morfología y aspecto de las colonias (masa constituida por bacterias que es visible a simple vista en la superficie de los medios sólidos de colora café a marrón), capacidad de crecer a una determinada temperatura, crecimiento en medios selectivos diferenciales y movilidad, la bacteria encontrada fue identificada en el laboratorio, las características morfológicas fueron observadas bajo el microscopio, cuyas características visuales se asociaron al género Erwinia. Una vez transcurridas 24 y $48 \mathrm{~h}$ de desarrollo, se comenzó corroborando a todos la pureza del cultivo, su morfología macroscópica y microscópica mediante tinción de Gram (Schaad, 1994).

Metodología para la identificación de Verticillium sp. (Punta de cigarro). El monitoreo de Punta de cigarro, se realizó quincenalmente, este se hizo colectando partes de la planta (frutos) con signos y síntomas de enfermedades, se utilizó un formato de registro de la cantidad de frutos dañados encontradas en cada sitio de muestro/día/parcela, luego depositadas dentro de un termo con hielo para el transporte del campo a los laboratorios de fitopatología del IPSA en Rivas y de la UNA en Managua.

Evaluación de punta de cigarro. Para determinar el porcentaje de incidencia de enfermedades se utilizó fórmula:

$$
\text { Incidencia }(\%)=\frac{\text { numero de hojas muestreadas con sintomas }}{\text { Total de hojas muestreados }} \times 100
$$

\section{Identificación y descripción de Punta de cigarro en laboratorio}

Análisis patológico de material vegetativo. Para realizar el análisis patológico del material vegetativo, se utilizaron técnicas de inducción de crecimiento de hongos, a partir de tejido vegetal enfermo posteriormente se sembró en medios de cultivos: Agar-Agua (AA) y Papa Dextrosa Agar (PDA para inducir la esporulación de estructuras reproductivas del patógeno. 
Cámara húmeda. Las muestras de tejido vegetal enfermo (frutos) se colocaron en platos petri o cajas plásticas con papel filtro, humedecido con agua destilada estéril para inducir a la esporulación de estructuras fructíferas de los hongos y su posterior identificación mediante el uso de microscopio.

\section{Siembra de trozos de frutos con estructuras fructíferas} y tejido infectado en AA y PDA. Primeramente se tomaron frutos con síntomas, se realizaron pequeños cortes en el fruto de manera que solo quedara en la lesión la estructura, luego se dejó reposar en agua destilada estéril por un minuto, se secó con papel filtro y se dejó reposar por 30 segundos, finalmente se sembró en platos petri con Agar-Agua (AA). Este procedimiento es el de inducir el desarrollo y crecimiento de estructuras de reproducción, tanto de fase sexual como. Para la siembra de trozos de hojas con tejido infectado en medio de cultivo papa dextrosa agar (PDA), las muestras fueron primeramente desinfectadas en alcohol al $95 \%$ por 1 minuto, posteriormente se sembraron en platos Petri con PDA; estos platos petri se rotularon de la siguiente manera: nombre del cultivo, fecha de muestreo y nombre de la parcela. Finalmente, los platos se preservaron a temperaturas de 2530 grados centígrados. Estos platos se revisaban diariamente con el propósito de observar estructuras reproductivas.

Identificación de punta de cigarro. El género de hongo encontrado fue identificado utilizando claves taxonómicas propuestas por (Monterrosa, 1996). Las características morfológicas o de crecimiento se observaron en microscopio.

Para el procesamiento de las muestras en el laboratorio de micología se realizó de la siguiente manera: Se lavó con agua de chorro introduciendo el material en una bolsa plástica, agitándose y realizando varios lavados en forma de enjuague hasta que la muestra se observó completamente limpia.

Se seleccionaron áreas de tejido enfermo y se seccionaron con bisturí, cuando se obtuvieron los trozos convenientes para el montaje de las muestras se procedió a desinfectar el material seccionado utilizando hipoclorito de sodio $(\mathrm{NaClo})$ al $5 \%$, con tiempos que van de uno a tres minutos, una vez desinfectada la muestra y previo a la siembra se colocó papel filtro estéril para secar el agua.

La siembra de las muestras se efectuó de la siguiente manera: Se colocaron los trozos desinfectados (aproximadamente 5 trozos por pato petri) en el medio de cultivo, se maceró la muestra y se rayó en medio de cultivo PDA. Una vez crecido el hongo en el medio de cultivo, se procedió a identificar la estructura del hongo bajo el microscopio.

\section{Variables evaluadas}

Porcentaje de severidad de daño de Mycosphaerella fijiensis Área bajo la curva de progreso de la enfermedad de Mycosphaerella fijiensis.

Porcentaje de incidencia de daño de Erwinia sp.

Porcentaje de incidencia de daño de Verticillium sp.

Análisis estadístico de los datos. Después de colectados los datos, estas fueron arregladas por variables en una tabla de datos en excel, luego cada variable fue comparada entre fincas, efectuando un análisis de varianza, utilizando el programa de SAS (SAS, 2003). El nivel de significancia usado en el análisis fue de $(\mathrm{p}=0.05)$.

\section{RESULTADOS Y DISCUSIÓN}

Comparación del porcentaje de severidad de sigatoka. Se presentó entre enero a septiembre 2014 (Figura 1). En general se observa que la severidad de este agente causal reflejó un comportamiento similar en las seis fincas, se presentó en todos los meses de muestreo, sin embargo, los mayores porcentajes de severidad se presentó entre agosto y septiembre con porcentaje de $60 \%$ y $67 \%$ respectivamente.

Pérez et al. (2000) determinaron que los mayores valores de severidad de sigatoka acumuladas fueron obtenidos en los meses de lluvia con porcentajes entre $36.3 \%$ y $59.8 \%$.

Al realizar el análisis de varianza y separación de medias para comparar los promedios de severidad se Sigatoka Negra, no se encontró diferencias significativas ( $\mathrm{p}=0.1044$ ). Cuando el daño por Sigatoka es severo, solamente la primera hoja abierta o la que está enrollada está libre de síntomas. Las pecas iniciales de la enfermedad aparecen en la segunda y tercera hoja, las rayas en las hojas número tres, cuatro y cinco; rayas y manchas a partir de la sexta hoja en adelante. El principal daño de la enfermedad en las plantas es la reducción de la capacidad fotosintética de las hojas, este daño provoca debilitamiento y disminución en rendimiento. Una planta debe tener por lo menos 7 a 8 hojas funcionales a la floración, para impedir pérdidas en la calidad de la fruta y garantizar buenos rendimientos (Palencia et al., 2006).

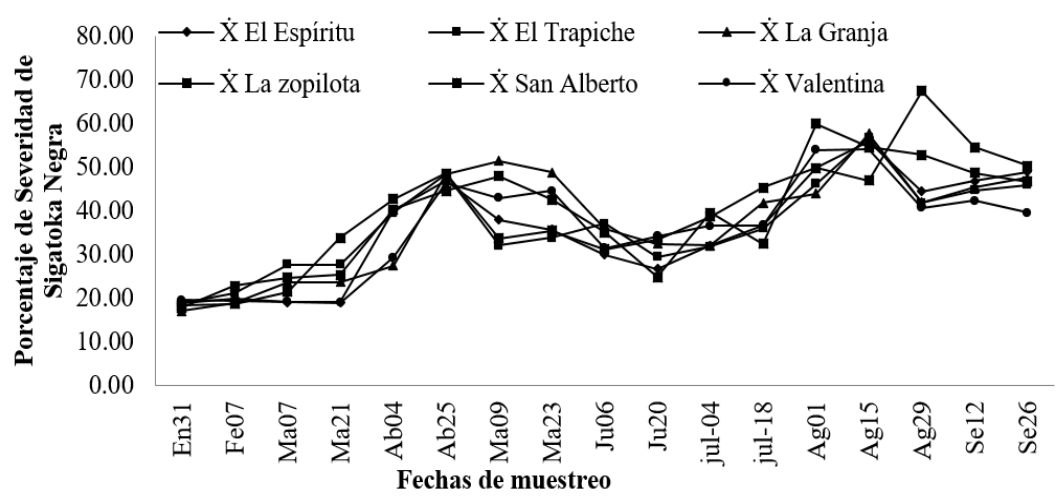

Figura 1. Porcentaje de severidad de Sigatoka Negra. 
Comparación del área bajo la curva del progreso de la enfermedad (ABCPE) de sigatoka. Se comparó el área bajo la curva de progreso de sigatoka negra en plátano, en seis fincas plataneras del departamento de Rivas, de enero a septiembre 2014 se presenta en la (Figura 2). La mayor área bajo la curva se presentó en la finca La Zopilota, seguido de San Alberto y La Granja, esto significa mayor oportunidad o mejores condiciones de la enfermedad para que progrese una epifítia mucho más rápido en estas fincas que en las otras, en cambio la menor área bajo la curva se presentó en la finca El Espíritu, El Trapiche y La Valentina.

Cuéllar et al. (2011), en su investigación sobre evaluación de resistencia de genotipos de plátano y banano a la sigatoka negra (Mycosphaerella fijiensis Morelet.), realizada en Colombia, encontraron que el ABCPE se comporta de manera similar que en este estudio. A la vez Carlier et al. (2000), en su estudio sobre mancha foliar por Septoria del banano: una enfermedad recientemente descubierta causada por Mycosphaerella eumusae Crous \& X. Mourichon (Anamorph Septoria eumusae) en Tailandia, coinciden que el comportamiento del ABCPE asciende en condiciones de humedad relativa, al igual que esta investigación.

Al realizar el análisis de varianza y separación de medias para comparar los promedios de ABCPE de Sigatoka Negra, no se encontró diferencias significativas $(p=0.1044)$.

Cuadro 2. Análisis de varianza del porcentaje de severidad de Sigatoka negra en seis fincas plataneras del departamento de Rivas 2014

\begin{tabular}{cc}
\hline \% Severidad de Sigatoka & \\
\hline Fincas & Media \pm ES \\
San Alberto & $38.92 \pm 0.70$ \\
La Zopilota & $37.75 \pm 0.70$ \\
La Granja & $37.58 \pm 0.67$ \\
El Trapiche & $37.20 \pm 0.64$ \\
Valentina & $37.08 \pm 0.73$ \\
El Espíritu & $36.06 \pm 0.69$ \\
CV & 38.18 \\
$P$ & $0.1044(\mathrm{NS})$ \\
gl, F, n & $2544,1.83,2550$ \\
\hline
\end{tabular}

Si $p=\leq 0.05$ es significativo $(\infty=0.05)$, de lo contrario es no significativo. R2 es el coeficiente de determinación. C.V: Coeficiente de variación; GL: Grados de libertad; P.V: Valor de la probabilidad.

Comparación del porcentaje de incidencia de la pudrición acuosa (Erwinia sp.). De manera general se observó que la incidencia de este agente causal reflejó un comportamiento similar en las seis fincas, se presentó en todos los meses de muestreo, los mayores porcentajes de incidencia se presentaron en los meses de febrero y fgosto del 2014 con porcentaje de $50 \%$ en ambas fechas.

Ramírez et al. (2014) en su estudio manejo alternativo de la pudrición acuosa del pseudotallo (Dickeya sp.) en Banano (Musa sp.). En Colombia, indican que los más altos porcentajes de incidencia del patógeno se muestran de la misma forma que en nuestro estudio.

Al mismo tiempo (Tripathi et al., 2009). En su investigación. Xanthomonas wilt. A threat to banana production in East and Central África, encontraron que la diseminación de esta bacteria es rápida y es eficientemente transmitida por contacto (herramientas del campo) produciendo pérdidas considerables. Se ha encontrado atacando indiscriminadamente todos los genotipos de bananos. Las fuentes de inóculo son los residuos de plantas enfermas, el suelo contaminado y describen el comportamiento de pudrición acuosa de manera idéntica que en este estudio.

El síntoma inicial de Erwinia que se observó en el campo consistió en lesiones acuosas, de color amarillento al comienzo y color oscuro al final, de olor fétido. Normalmente la enfermedad aparece en la mitad del pseudotallo y avanza hacia el centro y hacia abajo hasta llegar al cormo. Como consecuencia de la obstrucción de los tejidos, las hojas se van amarillando hasta secarse totalmente.

La enfermedad se transmite de una planta enferma a una sana principalmente durante el deshoje, por medio de herramientas usadas en labres de campo (Palencia et al., 2006).

Al realizar el análisis de varianza y separación de medias para comparar los promedios de incidencia se Erwinia, no se encontró diferencias significativas $(\mathrm{P}=0.58)$ (Cuadro 3). 


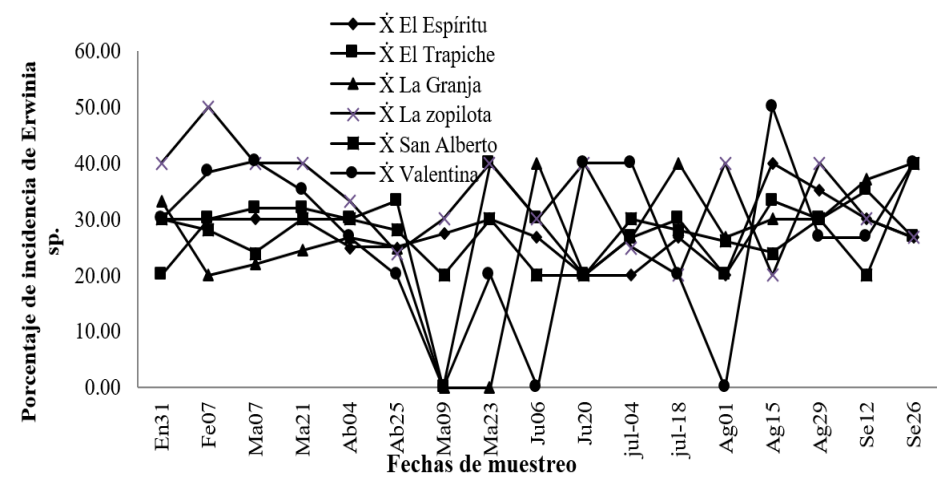

Figura 3. Porcentaje de incidencia de Erwinia sp. En seis fincas plataneras del departamento de Rivas 2014.

Cuadro 3. Análisis de varianza del porcentaje de incidencia de Erwinia sp. En seis fincas plataneras del departamento de Rivas 2014

\begin{tabular}{cc}
\hline Fincas & Media \pm ES \\
\hline La Granja & $32.41 \pm 2.70$ \\
La Zopilota & $32.34 \pm 1.97$ \\
Valentina & $32.30 \pm 2.73$ \\
El Trapiche & $30.76 \pm 2.18$ \\
El Espíritu & $30.00 \pm 2.02$ \\
San Alberto & $27.56 \pm 1.79$ \\
CV & 42.85 \\
$p$ & $0.58(\mathrm{NS})$ \\
$\mathrm{gl}, \mathrm{F}, \mathrm{n}$ & $212 ; 0.75 ; 218$ \\
\hline
\end{tabular}

Si $p=\leq 0.05$ es significativo $(\infty=0.05)$, de lo contrario es no significativo. R2 es el coeficiente de determinación. C.V: Coeficiente de variación; GL: Grados de libertad; P.V: Valor de la probabilidad.

\section{Comparación del porcentaje de incidencia de Verticillium} $s p$. (punta de cigarro) en seis fincas plataneras del departamento de Rivas. Se comparó y describió la incidencia de daño de Punta de cigarro en el cultivo del plátano. De manera general se observó que la incidencia de este agente causal reflejó un comportamiento similar en las seis fincas, se presentó en todos los meses de muestreo, sin embargo, los mayores porcentajes de incidencia se presentaron en los meses de enero y septiembre del 2014 con porcentaje de 7 y $11 \%$ respectivamente.

Cedeño y Carrero (1994) describen y reflejan en su estudio sobre incidencia de punta negra del plátano en Colombia, que el comportamiento de Verticillium todo el año y lo relacionan con la presencia de abejas negras del plátano como es Trigoma sp.

El inicio de la infección y el desarrollo de la punta de cigarro, están ligados a la alta humedad ambiental, razón por la cual, la enfermedad se observa durante la estación lluviosa, el patógeno penetra en frutos jóvenes a través de los restos de la flor que quedan adheridos a estos o bien a través de heridas ocasionadas por insectos como avispas o congos (Trigona sp) (Carcache, 2000).

$\mathrm{Al}$ realizar el análisis de varianza y separación de medias para comparar los promedios de incidencia se punta de cigarro, no se encontró diferencias significativas $(\mathrm{p}=0.18)$.

El fruto infectado presenta un ennegrecimiento inicial en la punta, la lesión se seca y al crecer el hongo sobre la parte muerta, esta última toma una forma idéntica a la ceniza de un cigarro, de ahí el nombre de la enfermedad. Para evitar la enfermedad deben eliminarse a mano los restos de la flor (pistilos) en los dedos que inician a formarse. Esto se conoce como des florillado. Un buen arreglo y distribución de las plantas en el terreno de manera que permita la entrada de aire y sol es muy importante para el manejo de la enfermedad, ya que de esta manera se elimina rápidamente cualquier exceso de humedad. Las aspersiones de fungicidas que se dan en el plátano para el control de la sigatoka, ayudan también a combatir esta enfermedad (Carcache, 2000).

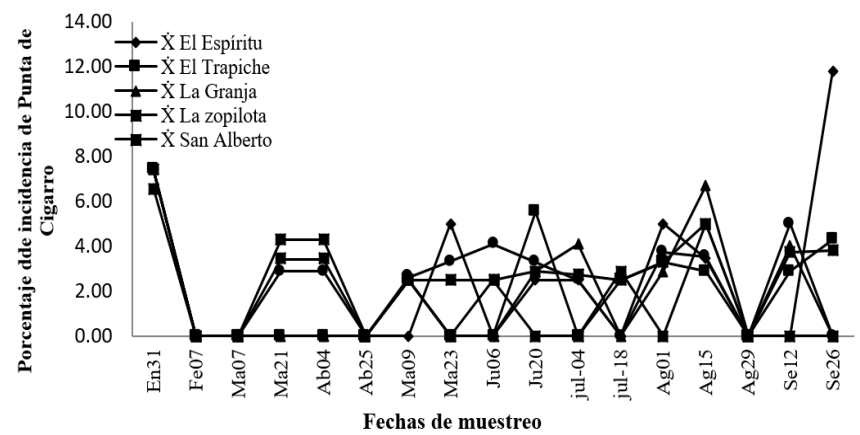

Figura 4. Porcentaje de incidencia de Verticillium sp. En seis fincas plataneras del departamento de Rivas 2014.

Cuadro 4. Análisis de varianza del porcentaje de incidencia de Verticillium sp. En seis fincas plataneras del departamento de Rivas 2014

\begin{tabular}{cc}
\hline Fincas & Media \pm ES \\
\hline El Espíritu & $7.06 \pm 2.06$ \\
La Granja & $5.00 \pm 0.89$ \\
El Trapiche & $4.58 \pm 0.78$ \\
La Zopilota & $4.27 \pm 0.68$ \\
Valentina & $4.08 \pm 0.51$ \\
San Alberto & $4.07 \pm 0.39$ \\
CV & 78.91 \\
$P$ & $0.18(\mathrm{NS})$ \\
gl, F, n & $107 ; 1.52 ; 113$ \\
\hline
\end{tabular}

Si $p=\leq 0.05$ es significativo $(\infty=0.05)$, de lo contrario es no significativo. R2 es el coeficiente de determinación. C.V: Coeficiente de variación; GL: Grados de libertad; P.V: Valor de la probabilidad. 


\section{CONCLUSIONES}

Se identificó a Mycosphaerella fijiensis, Erwinia sp. Y Verticillium sp. Como los principales agentes patógenos de enfermedades asociadas al cultivo del plátano en Rivas, Nicaragua.

Los meses de mayo a septiembre fue el periodo donde se encontró mayor presencia de incidencia, severidad y ABCPE de las enfermedades, comparados con los meses de enero a abril donde los porcentajes fueron menores.

\begin{abstract}
AGRADECIMIENTO
Los autores de esta investigación agradecen a la Universidad Nacional Agraria (UNA), al Instituto de Protección y Sanidad Agropecuaria (IPSA) y al Departamento de Agricultura de los Estados Unidos (USDA) por la financiación económica de este estudio.
\end{abstract}

\section{REFERENCIAS BIBLIOGRÁFICAS}

Carcache, M. (2000). Las enfermedades de plátano. Cuaderno de Campo para reconocimiento de las enfermedades. Escuela Internacional de Agricultura y Ganadería. Instituto Nicaragüense de Tecnología Agropecuaria. Comité Nacional de Manejo Integrado de Plagas.

Carlier, J., Fouré, E., Gauhl, F., Jones D. R., Lepoivre, P., Mourichon, X., Pasberggauhl, C. y Romero, R. A. (2000). Black leaf streak. En D.R Jones (Ed.), Diseases of Banana, Abacá and Enset (pp. 37-79). CAB International.

Carlier, J., Zapater, M. F., Lapeyre, F., Jones, D. R. y Mourichon, X. (2000). Septoria Leaf Spot of Banana: A Newly Discovered Disease Caused by Mycosphaerella eumusae (Anamorph Septoria eumusae). Phytopathology, 90(8), 884-890. https://doi.org/10.1094/ PHYTO.2000.90.8.884

Cedeño, L. y Carrero, C. (1994). Incidencia de punta negra del plátano.

Cuéllar, A., Álvarez, E. y Castaño, J. (2011). Evaluación de Resistencia de Genotipos de Plátano y Banano a la Sigatoka Negra (Mycosphaerella fijiensis Morelet.). Rev. Fac.Nal.Agr.Medellín, 64(1), 5853-5865. https://revistas.unal.edu.co/index.php/refame/ article/view/26392

Fernández, A., García, C. y Valdezate, S. (2010). Métodos de identificación bacteriana de microbiología. https://rb.gy/i0ldfl

Fouré, E. (1982). Les Cercosporioses du bananier et leurs traitements. Comportement des variétés. Etude de la sensibilité variétale des bananiers et plantains à Mycosphaerella fijiensis Morelet au Gabon (Maladie des raies noires.). I. Incubation et évolution de la maladie. Fruits, 37 (12), 749-759.

Heslop-Harrison, J. S. y Schwarzacher, T. (2007). Domestication, genomics and the future for banana. Annals of Botany, 100 (5), 10731084. https://doi.org/10.1093/aob/mcm191

Jiménez-Martínez, E. y Rodríguez, O. (2014). Insectos plagas de cultivos en Nicaragua. Universidad Nacional Agraria. https:// repositorio.una.edu.ni/2700/1/NH10J61ip.pdf

Jones, D. R. (2000). Disease of banana, abaca and ensete. CABI Publishing.

Mairena, R. (2003) Guía práctica para laboratorio de diagnóstico fitopatológico (2da ed.). Instituto de Protección y Sanidad Agropecuaria.

Martínez, K. I. (2018). Identificación de la problemática en la exportación del cultivo de plátano, en el departamento de Rivas, Nicaragua Septiembre - Noviembre 2018 [Tesis de maestría, Universidad Nacional Agraria]. Repositorio Institucional UNA. https://repositorio.una.edu.ni/3843/1/tne71m385.pdf

Ministerio de Fomento, Industria y Comercio. (2009). Ficha del plátano. https://es.scribd.com/document/95065337/ Ficha-Platano

Monterrosa, D. (1996). Técnicas fitopatológicas de laboratorio para el diagnóstico de las enfermedades de las plantas. Proyecto CATIE INTA-MIP (NORAD).

Palencia, G. E., Gómez, R. y Martín, J. E. (2006). Manejo sostenible del cultivo del plátano. Corporación Colombiana de Investigación Agropecuaria. https://repository.agrosavia.co/handle/20.500.12324/12888

Pérez, L. A., Hernández, A. y Porras, A. (2000). Epidemiología de la Sigatoka Negra (Mycosphaerella fijiensis Morelet) en Cuba. II. Pronóstico Bio-Climático de los Tratamientos contra la Enfermedad en Plátanos (Musa spp. AAB). Revista Mexicana de Fitopatología, 18(1), 27-35. https://www.redalyc.org/pdf/612/61218104.pdf

Ramírez, J. G., Jaraba, A. B. y Buriticá, P.E. (2014). Manejo de la pudrición acuosa del pseudo-tallo (Dickeya sp.) en banano (Musa sp.) bajo condiciones de invernadero. Agronomía Costarricense, 38(2), 83-92. https://www.redalyc.org/pdf/436/43632676007.pdf

SAS Institute. (2003). Statistical Analysis System. (versión 9.1) [software].

Schaad, N. W. (1994). Laboratory guide for identification of plant pathogenic bacteria (2da ed.). American Phytopathological Society.

Shaner, G. y Finney, R. (1977). The effect of Nitrogen fertilization on the expression of slow-mildewing resistance in knox wheat. Phytopathology, (67), 1051-1056. https://www.doi.org/10.1094/Phyto-67-1051

Tripathi, L., Mwangi, M., Abele, S., Aritua, V., Tushemereirwe, W.K. y Bandyopadhyay, R. (2009). Xanthomonas Wilt: A Threat to Banana Production in East and Central Africa. Plant Disease, 93(5). https://www.doi.org/10.1094/PDIS-93-5-0440

Vanderplank, J. E. (1968). Disease Resistance in Planst. Academic Press. 